\title{
Comparing Outcomes of Airway Changes and Risk of Sleep Apnea after Bimaxillary Orthognathic Surgery and Mandibular Setback Surgery in Patients with Skeletal Class III Malocclusion: A Systematic Review and Meta-Analysis
}

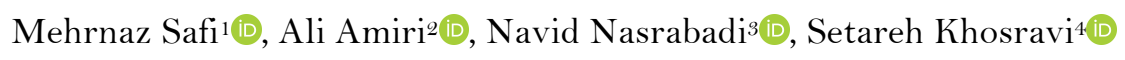

\begin{abstract}
'Department of Pedodontics, Dental School, Zanjan University of Medical Sciences, Zanjan, Iran.
'Department of Orthodontics, College of Stomatology, The First Affiliated Stomatological Hospital, Xi'an Jiaotong University, Xi'an 710004, PR China.

${ }^{3}$ Department of Endodontics, School of Dentistry, Shahid Beheshti University of Medical Sciences, Tehran, Iran.

${ }^{4}$ Department of Orthodontics, School of Dentistry, Shahed University, Tehran, Iran.
\end{abstract}

Correspondence: Ali Amiri, Department of Orthodontics, College of Stomatology, The First Affiliated Stomatological Hospital, Xi’an Jiaotong University, Xi'an 710004, PR China. E-mail: draliamiri2020@gmail.com

Academic Editor: Alessandro Leite Cavalcanti

Received: 12 October 2020 / Review: 02 December 2020 / Accepted: 08 December 2020

How to cite: Safi M, Amiri A, Nasrabadi N, Khosravi S. Comparing outcomes of airway changes and risk of sleep apnea
after bimaxillary orthognathic surgery and mandibular setback surgery in patients with skeletal class III malocclusion: a
systematic review and meta-analysis. Pesqui Bras Odontopediatria Clín Integr. 2021; $21: e 0222$.
https://doi.org/10.1590/pboci.2021.064

\begin{abstract}
Objective: To compare the airway changes and risks of sleep apnea after the bimaxillary orthognathic surgery and mandibular setback surgery in the growing patients with skeletal Class III malocclusion. Material and Methods: MEDLINE, PubMed, Cochrane Library, Embase, ISI, Google scholar have been utilized as the electronic databases for performing systematic literature between 2010 to August 2020. The quality of the included studies has been assessed using MINORS. Meta-analysis was performed using Stata 16 software. Results: In electronic searches, a total of 218 potentially relevant abstracts and topics have been found. Finally, 23 papers met the criteria defined for inclusion in this systematic review. The mean difference of upper airway total volume changes between before and after surgery was (MD $=1.86 \mathrm{~cm}^{3} 95 \%$ CI $\left.0.61 \mathrm{~cm}^{3}-3.11 \mathrm{~cm}^{3} ; \mathrm{p}=0.00\right)$ among 14 studies. This result showed that after Mandibular Setback Surgery, there was a statistically significant decrease in the upper airway volume. Conclusion: Class III Patients who undergo bimaxillary surgery show no other significant difference in airways volume after surgery than patients in Class III who undergo mandibular setback alone.
\end{abstract}

Keywords: Malocclusion, Angle Class III; Orthognathic Surgery; Sleep Apnea Syndromes. 


\section{Introduction}

Class III malocclusion could be characterized as a skeletal facial deformity joint in the clinical cases described by forwarding the mandibular position about the cranial base and maxilla [1]. Moreover, malocclusion may cause trouble in eating, breathing, and talking. A few children may have gum disease and jaw joint issues, too [2].

The Le Fort I maxillary osteotomy is the foremost common surgical method to redress the dentofacial deformities, including the maxilla, and it was more successful than that of mandibular [3]. Over the 1970s, orthodontic treatment was combined with orthognathic surgery for malocclusion redress because malocclusion issues may reoccur after following a surgical operation because of the traction of the soft tissues and the muscle forces created in the course of its function. This method also led to stable and desirable impacts [4], and thus it has been proved that it is a tool with the most significant effect to treat the skeletal Class III malocclusion [5]. Also, probable postsurgical changes can modify the location and traction of the around soft tissues, muscles, hyoid bone, soft palate, and tongue, location as well as the traction of the around Soft tissues, tongue, soft palate, muscles, and hyoid bone, and may alter the airway volumes and an estimate of the oral and nasal cavity $[6,7]$.

Dynamic changes in airway anatomy may also contribute to obstructive sleep apnea [8]. The mandibular setback surgery (MdS) effect on the association of the soft tissue and skeletal tissue has been also demonstrated that could result in a relative reduction of the pharyngeal airway space [9,10].

Bimaxillary orthognathic surgery is essentially the combination of armamentaria for maxillary and mandibular, so that adjustment of the Class III malocclusion expanded the total airway volume [10]. Hence, modification in the upper airway space through diverse orthognathic surgery is questionable [4,9-11]. Therefore, it is of particular significance to investigate the correlations between the risk of sleep apnea and changes in patients with Class III skeletal malocclusion in the upper airway.

Given the importance of this issue and the feeling of the need to research this area, the purpose of this systematic review and meta-analysis is to compare the results of changes in the airway and risk of sleep apnea after the bi-maxillary orthognathic surgery and mandibular setback surgery in with skeletal Class III malocclusion.

\section{Material and Methods}

Search Strategy

Between 2010 and August 2020, MEDLINE, PubMed, Cochrane Library, Embase, ISI, Google Scholar were used as electronic databases for systematic literature results. Then, Endnote x 8 software has been employed for electronically managing the titles. The search has been done with the keywords "mandibular setback, MdS, mandibular setback (MdS) surgery", "Class III malocclusion, malocclusion, or Angle Class III", "maxillary, mandibular", "sleep apnea, apnea-hypopnea, the obstructive sleep apnea, sleep apnea treatment, OSA, SA", "Bimaxillary Orthognathic, Bimaxillary Orthognathic Surgery, bimaxillary osteotomies", "crosssectional area OR CSA, cross-sectional area (CSA)", "upper airway, upper respiratory OR airways, respiratory", "Orthognathic Surgery, orthodontic treatment", "Cone-beam computed tomography, CBCT", and "Computer tomography or CT". The current systematic review was carried out based on the key considerations of the PRISMA Statement Preferred Reporting Items for the Systematic Review and Meta-analysis [12] as well as by the PICO strategy (Table 1). 
Table1. PICO OR PECO Strategy.

\begin{tabular}{cl}
\hline PICO or PECO & \multicolumn{1}{c}{ Description } \\
\hline $\mathrm{P}$ & Population/Patient: Patients with Class III Malocclusion \\
$\mathrm{E}$ & Exposure/Intervention: Bimaxillary Orthognathic Surgery or Mandibular Setback Surgery \\
$\mathrm{C}$ & Comparison: Pre-Surgery and Post-Surgery Parameters/Mandibular Setback vs. Maxillary Advancement \\
$\mathrm{O}$ & Outcome: Upper Airway Total Volume and Sleep Apnea \\
\hline
\end{tabular}

\section{Selection Criteria}

The following inclusion criteria were established: a) Randomized controlled trials studies, controlled clinical trial, prospective as well as retrospective cohort studies; b) Patients with Class III malocclusion; c) Changes of the upper airways; d) Evaluation sleep apnea before and after surgery; e) Conducted in the humans; f) CT and CBCT outcome; and g) Written in English. The following exclusion criteria were adopted: a) Case studies, clinical reports, case reports, and reviews; b) Incomplete data; and c) Animal studies.

\section{Data Extraction and Method of Analysis}

The following data were extracted from the research, including study, years, study design, sex, sample size, range, and mean age. The quality of the studies covered was evaluated using MINORS [13]. This methodological index had 12 items so that each case ranged between 0 and 2, and the total score equaled 24 (O$12=$ high risk of bias, 13 to $18=$ moderate risk of bias, and 19-24 = low risk). Two reviewers blinded and independently extracted data from the included studies for Data extraction. Moreover, mean differences with 95\% confidence interval (CI), the fixed-effect and inverse-variance methods were calculated. Random effects were used to resolve potential heterogeneity, and heterogeneity was demonstrated in $\mathrm{I}^{2}$. Meta-analysis was performed using Stata 16 Software (StataCorp LLC, Texas, USA).

\section{Results}

In the initial search with keywords, 584 articles were found. In the first step of the selection studies, 523 studies were selected to review the abstracts, and then 451 papers were excluded. In the second stage, the remaining 72 studies' full-text publications have been completely assessed. After that, 49 articles were excluded due to non-compliance with the inclusion criteria in this study and not report complete data. In the end, 23 papers met these crucial criteria to do a systematic review and meta-analysis (Figure 1). Thus 23 studies were included (Table 2 ).

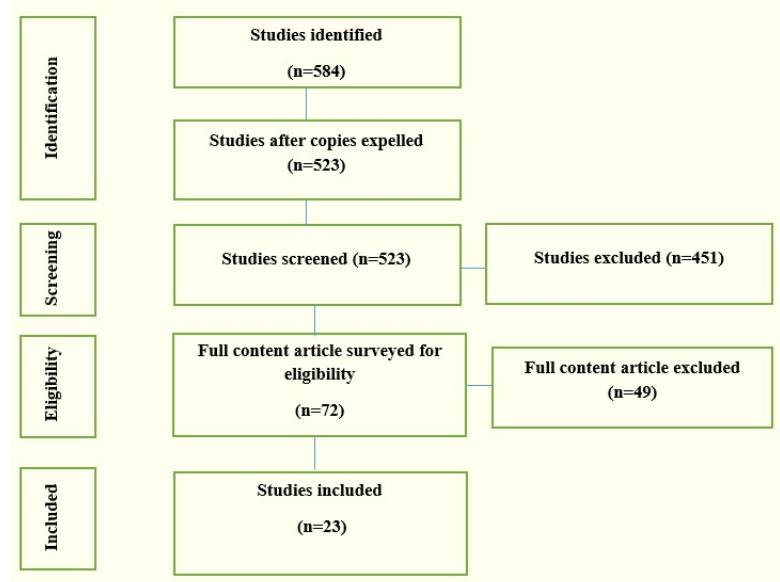

Figure 1. Study Attrition Diagram. 
Table 2. Studies selected for systematic review \& meta-analysis.

\begin{tabular}{|c|c|c|c|c|c|c|c|c|}
\hline \multirow[t]{2}{*}{ Study/Year } & \multirow[t]{2}{*}{ Study Design } & \multicolumn{2}{|c|}{ Sample Size } & \multirow{2}{*}{$\begin{array}{l}\text { Age (Years) } \\
\text { Mean-Range }\end{array}$} & \multirow[t]{2}{*}{ Sort of Surgery } & \multirow[t]{2}{*}{ Measurements } & \multirow[t]{2}{*}{ Quality Score by MINORS } & \multirow[b]{3}{*}{15} \\
\hline & & Male & Female & & & & & \\
\hline Agarwal et al. (2019) [14] & Retrospective & 5 & 5 & NA & Mandibular Setback & Upper Airway Total Volume & Parameters of Pre and Post-Surgery & \\
\hline On et al. (2019) [8] & Prospective & 29 & 21 & 21.86 & Mandibular Setback & $\begin{array}{l}\text { Upper Airway Total Volume } \\
\text { Apnea-hypopnea index (AHI) }\end{array}$ & Parameters of Pre and Post-Surgery & 18 \\
\hline Havron et al. (2019) [15] & Retrospective & & 14 & NA & Mandibular Setback & Upper Airway Total Volume & $\begin{array}{c}\text { Mandibular Setback + Maxillary } \\
\text { Advancement }\end{array}$ & 21 \\
\hline Cosmin Ioan et al. (2019) [16] & Prospective & & 9 & 27 & BOS & Upper Airway Total Volume & Parameters of Pre and Post-Surgery & 17 \\
\hline Jeong et al. (2018) [17] & Retrospective & 10 & 8 & 22.7 & Mandibular Setback & Upper Airway Total Volume & Parameters of Pre and Post-Surgery & 18 \\
\hline Tepecik et al. (2018) [18] & Prospective & 7 & 14 & NA & BOS & $\begin{array}{l}\text { Upper Airway Total Volume } \\
\text { Apnea-Hypopnea Index (AHI) }\end{array}$ & Parameters of Pre and Post-Surgery & 20 \\
\hline Jang et al. (2018) [19] & Prospective & & 13 & $>18$ & BOS & $\begin{array}{l}\text { Upper Airway Total Volume } \\
\text { Apnea-Hypopnea Index (AHI) }\end{array}$ & Parameters of Pre and Post-Surgery & 18 \\
\hline Vaezi et al. (2017) [20] & Prospective & 4 & 6 & 20.4 & BOS & Upper Airway Total Volume & Parameters of Pre and Post-Surgery & 16 \\
\hline Lee et al. (2017) [21] & Prospective & 5 & 17 & 22.1 & BOS & $\begin{array}{l}\text { Upper Airway Total Volume } \\
\text { Apnea-Hypopnea Index (AHI) }\end{array}$ & Parameters of Pre and Post-Surgery & 18 \\
\hline Kim et al. (2016) [22] & Prospective & 16 & 22 & 23.84 & Mandibular Setback & Upper Airway Total Volume & Parameters of Pre and Post-Surgery & 15 \\
\hline Canellas et al. (2016) [23] & Prospective & 11 & 22 & 24.5 & BOS & $\begin{array}{l}\text { Upper Airway Total Volume } \\
\text { Apnea-Hypopnea Index (AHI) }\end{array}$ & $\begin{array}{c}\text { Mandibular Setback + Maxillary } \\
\text { Advancement }\end{array}$ & 19 \\
\hline Azevêdo et al.(2016) [24] & Retrospective & 9 & 5 & $17-40$ & $\begin{array}{c}\text { Mandibular Setback } \\
\text { Maxillary Advancement }\end{array}$ & Upper Airway Total Volume & Parameters of Pre and Post-Surgery & 14 \\
\hline Hatab et al. (2015) [25] & Prospective & 9 & 11 & 21.7 & Mandibular Setback & Upper Airway Total Volume & $\begin{array}{c}\text { Mandibular Setback + Maxillary } \\
\text { Advancement }\end{array}$ & 20 \\
\hline Hsieh et al. (2015) [26] & Retrospective & 18 & 54 & 24.0 & Mandibular Setback & Upper Airway Total Volume & Parameters of Pre and Post-Surgery & 19 \\
\hline Wang et al. (2015) [27] & Prospective & 13 & 15 & 19 & Mandibular Setback & Upper Airway Total Volume & $\begin{array}{c}\text { Mandibular Setback + Maxillary } \\
\text { Advancement }\end{array}$ & 15 \\
\hline Hart et al. (2015) [28] & Retrospective & 31 & 40 & 19 & $\begin{array}{l}\text { Mandibular Setback + } \\
\text { Maxillary Advancement }\end{array}$ & Upper Airway Total Volume & Parameters of Pre and Post-Surgery & 14 \\
\hline Burkhard et al. (2014) [29] & Retrospective & 3 & 8 & 26 & $\begin{array}{l}\text { Mandibular setback + } \\
\text { Maxillary Advancement }\end{array}$ & Upper Airway Total Volume & Parameters of Pre and Post-Surgery & 13 \\
\hline Li et al. (2014) [30] & Retrospective & 0 & 29 & 23 & $\begin{array}{l}\text { Mandibular Setback + } \\
\text { Maxillary Advancement }\end{array}$ & Upper Airway Total Volume & Parameters of Pre and Post-Surgery & 19 \\
\hline Uesugi et al. (2014) [31] & Prospective & 21 & 19 & 23 & Mandibular Setback & Upper Airway Total Volume & $\begin{array}{c}\text { Mandibular Setback + Maxillary } \\
\text { Advancement }\end{array}$ & 19 \\
\hline Park et al. (2012) [32] & Retrospective & 23 & 13 & 23 & $\begin{array}{l}\text { Mandibular Setback + } \\
\text { Maxillary Advancement }\end{array}$ & Upper Airway Total Volume & $\begin{array}{c}\text { Mandibular Setback + Maxillary } \\
\text { Advancement }\end{array}$ & 20 \\
\hline Hong et al. (2011) [33] & Retrospective & 14 & 7 & 27 & Mandibular Setback & Upper Airway Total Volume & Parameters of Pre and Post-Surgery & 19 \\
\hline Park et al. (2010) [34] & Retrospective & 5 & 7 & 26 & Mandibular Setback & Upper Airway Total Volume & Parameters of Pre and Post-Surgery & 14 \\
\hline Jakobsone et al. (2010) [35] & Prospective & 8 & 6 & 20 & $\begin{array}{l}\text { Mandibular Setback + } \\
\text { Maxillary Advancement }\end{array}$ & Upper Airway Total Volume & Parameters of Pre and Post-Surgery & 15 \\
\hline
\end{tabular}

$\overline{\text { BOS }}$ = Bimaxillary Orthognathic Surgery; Quality score by MINORS: 0-12 demonstrated the increased risks of bias, 13-18 for the moderate risks of bias, and 19 to 24 for lower risks of bias. 
The number of patients a total was 606, with 23.1 years mean of age. Mean difference of upper airway total volume changes between before and after mandibular setback was (MD $=2.26 \mathrm{~cm}^{3}, 95 \% \mathrm{CI}=0.36 \mathrm{~cm}^{3}$ $\left.4.16 \mathrm{~cm}^{3} ; \mathrm{p}=0.02\right)$ among six studies and heterogeneity found $\left(\mathrm{I}^{2}=64.27 \% ; \mathrm{p}=0.02\right)$. This result showed that after mandibular setback surgery, there was a statistically significant decrease in the upper airway volume (Figure 2). Also Figure 3 showed mean difference of upper airway total volume changes between before and after Bimaxillary orthognathic surgery was $\left(\mathrm{MD}=1.90 \mathrm{~cm}^{3}, 95 \% \mathrm{CI}=0.34 \mathrm{~cm}^{3}-3.45 \mathrm{~cm}^{3} ; \mathrm{p}=0.02\right)$ among ten studies and heterogeneity found $\left(\mathrm{I}^{2}=37.94 \% ; \mathrm{p}=0.011\right)$. Comparing this result, it turns out that bimaxillary surgery promotes less decrease than mandibular setback.

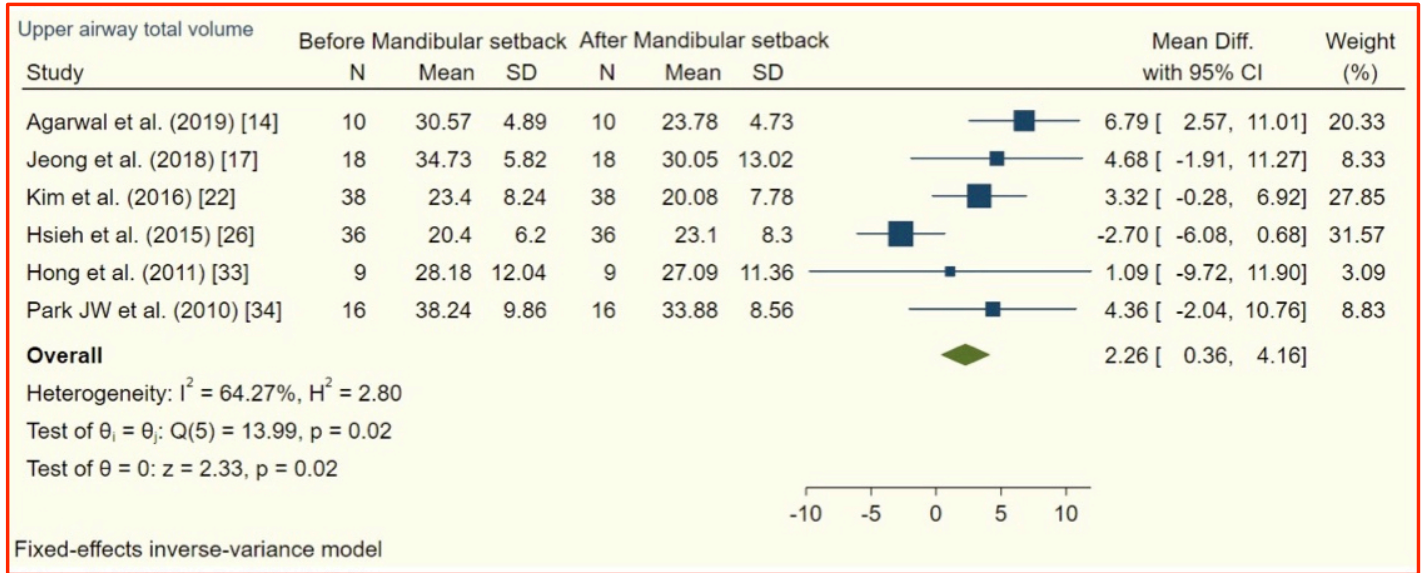

Figure 2. Forest plots showed upper airway total volume changes between before and after mandibular setback.

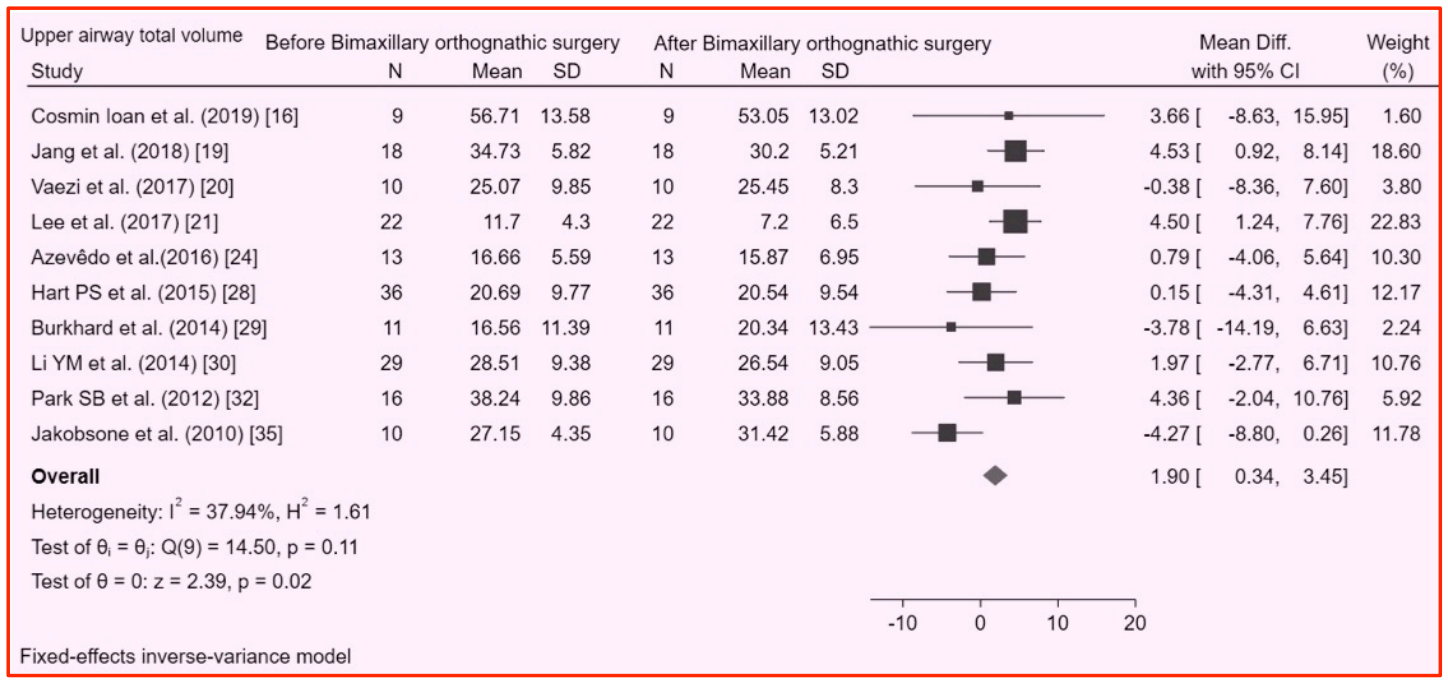

Figure 3. Forest plots showed upper airway total volume changes between before and after Bimaxillary orthognathic surgery.

Mean difference of upper airway total volume changes between 1-jaw and 2-jaw surgery was $(\mathrm{MD}=$ $\left.0.95 \mathrm{~cm}^{3}, 95 \% \mathrm{CI}=-1.37 \mathrm{~cm}^{3}-3.28 \mathrm{~cm}^{3}, \mathrm{p}=0.42\right)$ among 5 studies and heterogeneity found $\left(\mathrm{I}^{2}=61.80 \%\right.$, $\mathrm{p}=0.03)$. This result showed no statistically significant decrease in the upper airway volume between 1 -jaw and 2-jaw (Figure 4). 


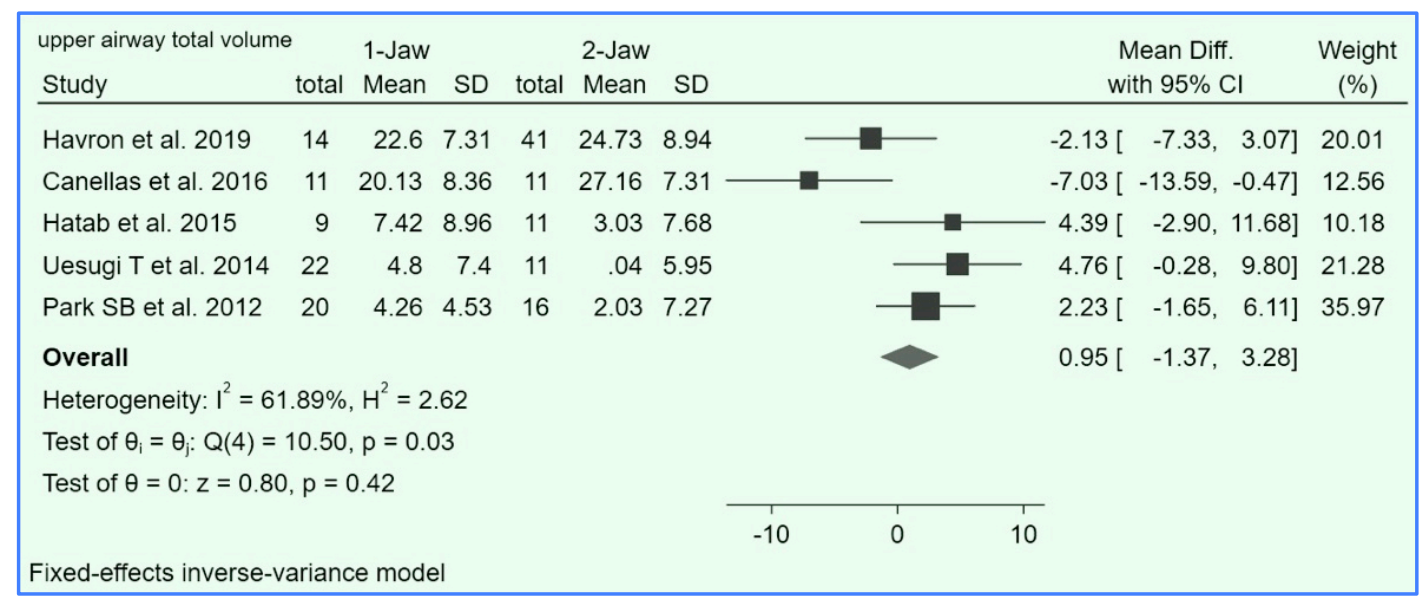

Figure 4. Forest plots showed upper airway total volume changes between 1-jaw and 2-jaw.

Mean difference of apnea-hypopnea index (AHI) between before and after orthognathic surgery was (MD $=0.01,95 \% \mathrm{CI}=-0.51-0.54, \mathrm{p}=0.96)$ among 5 studies and heterogeneity found $\left(\mathrm{I}^{2}=48.37 \%\right.$; $\left.=0.10\right)$. This result showed no statistically significant results difference in sleep apnea after orthognathic surgery (Figure 5).

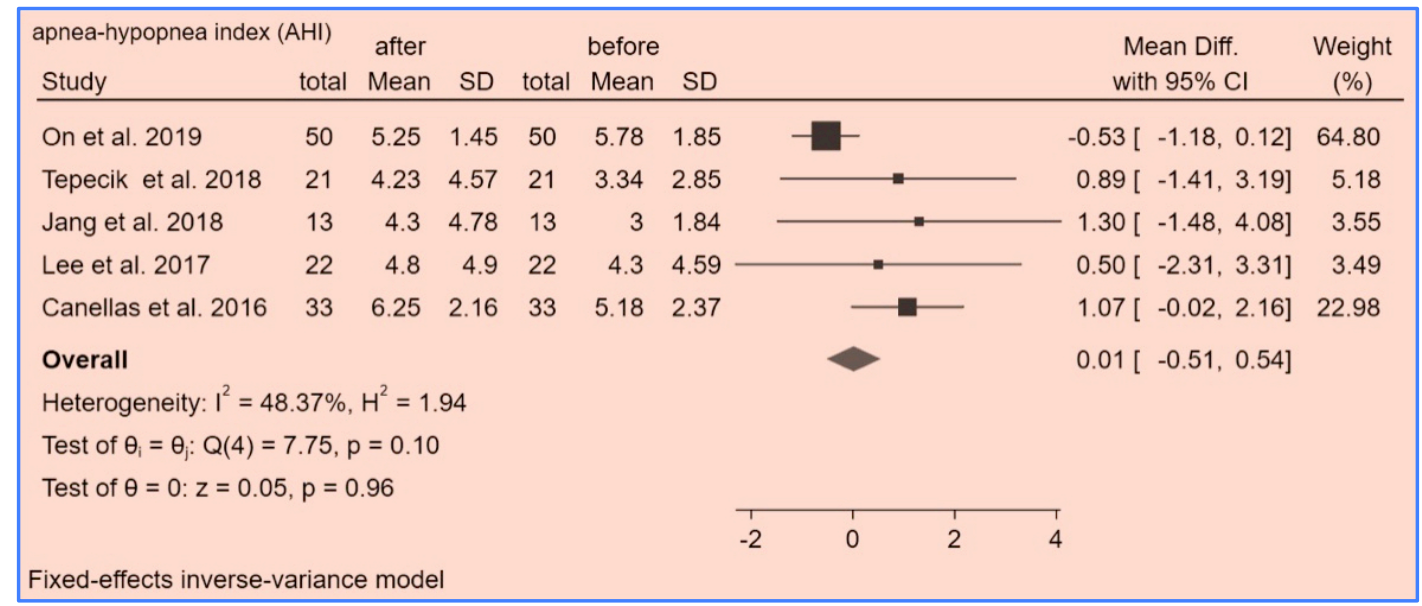

Figure 5. Forest plots showed apnea-hypopnea index (AHI) changes between before and after surgery.

Bias Assessment

According to the MINORS tool, none studies had a high risk of bias, 14 studies had a moderate risk of bias, and nine studies had low risk (Table1).

\section{Discussion}

Due to their anatomical structures, the upper airways were considered by surgeons and orthodontists because they can affect the health and quality of life of patients. An association has also been observed between the upper airways and obstructive sleep apnea syndrome [36]. The purpose of this systematic review and meta-analysis was a comparison of the outcomes of the airway changes and risk of sleep apnea after the bimaxillary orthognathic surgery and mandibular setback surgery in the growing patients with a severe, developing skeletal Class III malocclusion. The meta-analysis result showed the upper airway changes 
following the mandibular setback surgery equal to $1.86 \mathrm{~cm}^{3}$. It showed a statistically significant decrease in the upper airway volume before and after Mandibular Setback Surgery. Also, $0.95 \mathrm{~cm}^{3}$ upper airway changes showed between 1-jaw and 2-jaw surgery. As a result, there was no statistically significant decrease in the upper airway volume between 1-jaw and 2-jaw. The apnea-hypopnea index's mean difference showed 0.01 changes and no statistically significant difference in sleep apnea after orthognathic surgery.

Some studies did not report this change, while others indicated the upper airway [37-39]. Some studies also have shown that any significant difference changes have not been found between the upper airway [24] or lower volume significantly decreased [25-29,40,41]. The three-dimensional (3D) results showed that bi-maxillary orthognathic surgery considerably changed the soft palate and hyoid bone location. The pharyngeal airway space was significantly reduced in the correction of the skeletal Class III malocclusion [30]. The operation of the 2-jaws should be investigated in the skeletal Class III patients with the above risks because it reduces the amounts of the pharyngeal airway spaces due to the mandibular setback surgery [31]. A result of a systematic review and meta-analysis which has been done by He et al. [10] demonstrated a $3.24 \mathrm{~cm}^{3}$ $[95 \% \mathrm{CI}(-5.25,-1.23 ; \mathrm{p}=0.85]$ mean decrease in the upper airway volume following the MdS surgery; the almost the same as the results of the present study. This study also showed statistically significant differences between 2-jaw and 1-jaw, contrary to the present study results.

According to this meta-analysis, there has been no statistically significant increase in sleep apnea risk before and after surgery. A three-dimensional (3D) PAS volume showed a significant decrease in the oropharyngeal airway, and no significant change has been observed in the sleep symptoms [8]. Reports indicated that bimaxillary orthognathic surgery to reduce PAS played a role, but it does not increase AHI, one of the important determinants of sleep apnea [18,19,21,23]. As a result of a significant decrease in the airway space, it did not influence the AHI-values or cause OSA. In a systematic review conducted by Vancan et al. [42], 17 articles have been included, which reflected the role of orthognathic surgery in obstructive sleep apnea syndrome. However, this study did not mention the statistical dimensions and values of changes. Also, Faria et al. [43] compared the cephalometric radiographs and found a $0.76 \mathrm{~mm}$ increment within the retropalatal region and a $1.2 \mathrm{~mm}$ increment in a retro-lingual region in each millimeter ( $\mathrm{mm}$ ) of the maxillomandibular progression.

Nonetheless, skeletal relapse and airway compromise in the mandibular setback surgery cases and bimaxillary orthognathic surgery (as observed in this study) required a clinician to analyze and arrange the treatment in these cases fastidiously. Thus a more extensive Bi-jaw surgery may be considered at the cost of avoiding airway compromise in these patients. According to the existing studies, it is felt that longitudinal studies with high quality and larger sample size with a longer follow-up period would be necessary for the future.

\section{Conclusion}

In Class III patients undergoing mandibular setback surgery alone, a statistically significant decrease in total volume changes at the upper airway. Patients undergoing orthognathic surgery in Class III showed no significant difference in the apnea-hypopnea index after surgery compared to before surgery. Section III Patients undergoing bimaxillary surgery do not show any other significant difference in airways volume after surgery compared to patients undergoing mandibular setback alone. It is also possible that these two surgeries significantly narrowed the airway dimensions but did not cause an increase in the apnea-hypopnea index. 


\section{Authors' Contributions}

\begin{tabular}{|c|c|c|}
\hline MS & (iD) https://orcid.org/0000-0001-7260-0142 & Writing - Original Draft, and Writing - Review and Editing. \\
\hline AA & (D) https://orcid.org/0000-0001-94:16-808X & $\begin{array}{l}\text { Conceptualization, Methodology, Validation, Formal Analysis, Investigation, Data Curation, } \\
\text { Writing - Original Draft, Writing - Review and Editing, Visualization and Supervision. }\end{array}$ \\
\hline $\mathrm{NN}$ & (iD) https://orcid.org/0000-0002-6365-6619 & Writing - Original Draft, and Writing - Review and Editing. \\
\hline SK & (iD) https://orcid.org/0000-0002-7360-269X & Writing - Original Draft, and Writing - Review and Editing. \\
\hline
\end{tabular}

\section{Financial Support}

None.

\section{Conflict of Interest}

The authors declare no conflicts of interest.

\section{Data Availability}

The data used to support the findings of this study can be made available upon request to the corresponding author.

\section{References}

[1] Abdolreza J, Saeed K, Alireza D. Treatment Protocol for Skeletal Class III Malocclusion in Growing Patients. In: Motamedi MH. A Textbook of Advanced Oral and Maxillofacial Surgery Volume 3. London: IntechOpen; 2016.

[2] Kolawole KA, Folayan MO, Agbaje HO, Oyedele TA, Onyejaka NK, Oziegbe EO. Oral habits and malocclusion in children resident in Ile-Ife Nigeria. Eur Arch Paediatr Dent 2019; 20(3):257-65.

https://doi.org/10.1007/s40368-018-0391-3

[3] On SW, Baek SH, Choi JY. Quantitative Evaluation of the postoperative changes in nasal septal deviation by diverse movement of the maxilla after Le Fort I osteotomy. J Craniofac Surg 2020; 31(5):1251-5. https://doi.org/10.1097/SCS.0000000000006430

[4] He L, He S, Wu X, Huang Y. Three-dimensional morphological changes of the upper airway in patients with skeletal class iii malocclusion after orthognathic surgery. J Craniofac Surg 2019; 30(8):2451-5. https://doi.org/10.1097/SCS.0000000000005738

[5] Yen S, Hammoudeh J, Edwards SP, Urata M. Orthodontic considerations for cleft orthognathic surgery. Oral Maxillofac Surg Clin North Am 2020; 32(2):249-67. https://doi.org/10.1016/j.coms.2020.01.013

[6] Rana SS, Kharbanda OP, Agarwal B. Influence of tongue volume, oral cavity volume and their ratio on upper airway: A cone beam computed tomography study. J Oral Biol Craniofac Res 2020; 10(2):110-7. https://doi.org/10.1016/j.jobcr.2020.03.006

[7] Laird AM, Yetkiner E, Kadioglu O, Currier GF. The Upper Airway. In: Currier F, Currier GF. Craniofacial 3D Imaging: Current Concepts in Orthodontics and Oral and Maxillofacial Surgery. London: Springer International Publishing; 2019. pp. 97-112.

[8] On SW, Kim HJ, Cho DH, Moon YR, Song SI. Silent changes in sleep quality following mandibular setback surgery in patients with skeletal class III malocclusion: a prospective study. Sci Rep 2019; 9(1):1-10. https://doi.org/10.1038/s41598-019-46166-Z

[9] Fernández-Ferrer L, Montiel-Company JM, Pinho T, Almerich-Silla JM, Bellot-Arcis C. Effects of mandibular setback surgery on upper airway dimensions and their influence on obstructive sleep apnoea - A systematic review. $\mathrm{J}$ Craniomaxillofac Surg 2015; 43(2):248-53. https://doi.org/10.1016/j.jcms.2014.11.017

[10] He J, Wang Y, Hu H, Liao Q, Zhang W, Xiang X, et al. Impact on the upper airway space of different types of orthognathic surgery for the correction of skeletal class III malocclusion: A systematic review and meta-analysis. Int J Surg 2017; 38:31-40. https://doi.org/10.1016/j.ijsu.2016.12.033

[11] Abolhassani H, Tavakol M, Chavoshzadeh Z, Mahdaviani SA, Momen T, Yazdani R, et al. National consensus on diagnosis and management guidelines for primary immunodeficiency. Immunol Gen J 2019 ; $2(1): 1-21$. https://doi.org/10.22034/IGJ.2019.85743

[12] Panic N, Leoncini E, De Belvis G, Ricciardi W, Boccia S. Evaluation of the endorsement of the preferred reporting items for systematic reviews and meta-analysis (PRISMA) statement on the quality of published systematic review and meta-analyses. PloS one 2013; 8(12):e83138. https://doi.org/10.1371/journal.pone.0083138

[13] Slim K, Nini E, Forestier D, Kwiatkowski F, Panis Y, Chipponi J. Methodological index for non-randomized studies (MINORS): development and validation of a new instrument. ANZ J Surg 2003; 73(9):712-6. https://doi.org/10.1046/j.1445-2197.2003.02748.x

[14] Agarwal SS. Evaluation of pharyngeal airway dimensions following mandibular setback surgery in patients treated with surgery first orthognathic approach. J Sleep Disord Ther 2019; 8(302):1-5.

https://doi.org/10.4172/2167-0277.1000302 
[15] Havron AG, Aronovich S, Shelgikar AV, Kim HL, Conley RS. 3D Airway changes using CBCT in patients following mandibular setback surgery \pm maxillary advancement. Orthod Craniofac Res 2019; 22(Suppl 1):30-5. https://doi.org/10.1111/ocr.12291

[16] Faur CI, Roman RA, Bran S, Dinu C, Coclici A, Rotaru H, Hedesiu M. The changes in upper airway volume after orthognathic surgery evaluated by individual segmentation on CBCT images. Maedica 2019; 14(3):213-9. https://doi.org/10.26574/maedica.2019.14.3.213

[17] Jeong S, Sung J, Kim S, Kim Y, Shin S, Kim SS. Upper airway morphologic changes after mandibular setback surgery in skeletal class III malocclusion patients measured using cone beam computed tomography superimposition. Int J Oral Maxillofac Surg 2018; 47(11):1405-10. https://doi.org/10.1016/j.ijom.2018.05.002

[18] Tepecik T, Ertaş Ü, Akgün M. Effects of bimaxillary orthognathic surgery on pharyngeal airway and respiratory function at sleep in patients with class III skeletal relationship. J Craniomaxillofac Surg 2018; 46(4):645-53. https://doi.org/10.1016/j.jcms.2018.01.009

[19] Jang SI, Ahn J, Paeng JY, Hong J. Three-dimensional analysis of changes in airway space after bimaxillary orthognathic surgery with maxillomandibular setback and their association with obstructive sleep apnea. Maxillofac Plast Reconstr Surg 2018; 4O(1):33. https://doi.org/10.1186/s40902-018-0171-3

[20] Vaezi T, Zarch SH, Eshghpour M, Kermani H. Two-dimensional and volumetric airway changes after bimaxillary surgery for class III malocclusion. J Korean Assoc Oral Maxillofac Surg 2017; 43(2):88-93. https://doi.org/10.5125/jkaoms.2017.43.2.88

[21] Lee UL, Oh H, Min SK, Shin JH, Kang YS, Lee WW, et al. The structural changes of upper airway and newly developed sleep breathing disorders after surgical treatment in class III malocclusion subjects. Medicine 2017; 96(22):e687. https://doi.org/10.1097/MD.0000000000006873

[22] Kim HS, Kim GT, Kim S, Lee JW, Kim EC, Kwon YD. Three-dimensional evaluation of the pharyngeal airway using cone-beam computed tomography following bimaxillary orthognathic surgery in skeletal class III patients. Clin Oral Investig 2016; 20(5):915-22. https://doi.org/10.1007/s00784-015-1575-4

[23] Canellas JD, Barros HL, Medeiros PJ, Ritto FG. Effects of surgical correction of class III malocclusion on the pharyngeal airway and its influence on sleep apnoea. Int J Oral Maxillofac Surg 2016; 45(12):1508-12. https://doi.org/10.1016/j.ijom.2016.09.002

[24] Azevêdo MS, Machado AW, Barbosa ID, Esteves LS, Rocha VÁ, Bittencourt MA. Evaluation of upper airways after bimaxillary orthognathic surgery in patients with skeletal Class III pattern using cone-beam computed tomography. Dental Press J Orthod 2016; 21(1):34-41. https://doi.org/10.1590/2177-6709.21.1.034-041.oar

[25] Hatab NA, Konstantinović VS, Mudrak JK. Pharyngeal airway changes after mono-and bimaxillary surgery in skeletal class III patients: Cone-beam computed tomography evaluation. J Craniomaxillofac Surg 2015; 43(4):491-6. https://doi.org/10.1016/j.jcms.2015.02.007

[26] Hsieh YJ, Chen YC, Chen YA, Liao YF, Chen YR. Effect of bimaxillary rotational setback surgery on upper airway structure in skeletal Class III deformities. Plast Reconstr Surg 2015; 135(2):361e-9e. https://doi.org/10.1097/PRS.0000000000000913

[27] Wang H, Qi S, Yan M, Zhang C, Ren S, Zhang J. Cone-beam computed tomography evaluation of upper airway change in skeletal Class III patients after orthodontic-mandibular setback surgery. Zhonghua Kou Qiang Yi Xue Za Zhi 2015; 50(10):615-8.

[28] Hart PS, McIntyre BP, Kadioglu O, Currier GF, Sullivan SM, Li J, et al. Postsurgical volumetric airway changes in 2-jaw orthognathic surgery patients. Am J Orthod Dentofacial Orthop 2015; 147(5):536-46. https://doi.org/10.1016/j.ajodo.2014.12.023

[29] Burkhard JP, Dietrich AD, Jacobsen C, Roos M, Lübbers HT, Obwegeser JA. Cephalometric and three-dimensional assessment of the posterior airway space and imaging software reliability analysis before and after orthognathic surgery. J Craniomaxillofac Surg 2014; 42(7):1428-36. https://doi.org/10.1016/j.jcms.2014.04.005

[30] Li YM, Liu JL, Zhao JL, Dai J, Wang L, Chen JW. Morphological changes in the pharyngeal airway of female skeletal class III patients following bimaxillary surgery: a cone beam computed tomography evaluation. Int J Oral Maxillofac Surg 2014; 43(7):862-7. https://doi.org/10.1016/j.ijom.2014.03.009

[31] Uesugi T, Kobayashi T, Hasebe D, Tanaka R, Ike M, Saito C. Effects of orthognathic surgery on pharyngeal airway and respiratory function during sleep in patients with mandibular prognathism Int J Oral Maxillofac Surg 2014; 43(9):1082-90. https://doi.org/10.1016/j.ijom.2014.06.010

[32] Park SB, Kim YI, Son WS, Hwang DS, Cho BH. Cone-beam computed tomography evaluation of short-and longterm airway change and stability after orthognathic surgery in patients with Class III skeletal deformities: bimaxillary surgery and mandibular setback surgery. Int J Oral Maxillofac Surg 2012; 41(1):87-93. https://doi.org/10.1016/j.ijom.2011.09.008

[33] Hong JS, Park YH, Kim YJ, Hong SM, Oh KM. Three-dimensional changes in pharyngeal airway in skeletal class III patients undergoing orthognathic surgery. J Oral Maxillofac Surg 2011; 69(11):e401-8. https://doi.org/10.1016/j.joms.2011.02.011 
[34] Park JW, Kim NK, Kim JW, Kim MJ, Chang YI. Volumetric, planar, and linear analyses of pharyngeal airway change on computed tomography and cephalometry after mandibular setback surgery. Am J Orthod Dentofacial Orthop 2010; 138(3):292-9. https://doi.org/10.1016/j.ajodo.2009.10.036

[35] Jakobsone G, Neimane L, Krumina G. Two-and three-dimensional evaluation of the upper airway after bimaxillary correction of Class III malocclusion. Oral Surg Oral Med Oral Pathol Oral Radiol Endod 2010; 110(2):234-42. https://doi.org/10.1016/j.tripleo.2010.03.026

[36] Cui DM, Han DM, Nicolas B, Hu CL, Wu J, Su MM. Three-dimensional evaluation of nasal surgery in patients with obstructive sleep apnea. Chin Med J (Engl) 2016; 129(6):651. https://doi.org/10.4103/0366-6999.177971

[37] Pereira-Filho VA, Castro-Silva LM, de Moraes M, Gabrielli MF, Campos JA, Juergens P. Cephalometric evaluation of pharyngeal airway space changes in class III patients undergoing orthognathic surgery. J Oral Maxillofac Surg 2011; 69(11):e409-15. https://doi.org/10.1016/j.joms.2011.02.132

[38] Aydemir H, Memikoğlu U, Karasu H. Pharyngeal airway space, hyoid bone position and head posture after orthognathic surgery in Class III patients. Angle Orthod 2012; 82(6):993-1000.

https://doi.org/10.2319/091911-597.1

[39] Hwang S, Chung CJ, Choi YJ, Huh JK, Kim KH. Changes of hyoid, tongue and pharyngeal airway after mandibular setback surgery by intraoral vertical ramus osteotomy. Angle Orthod 2010; 80(2):302-8. https://doi.org/10.2319/040209-188.1

[40] Gokce SM, Gorgulu S, Gokce HS, Bengi AO, Karacayli U, Ors F. Evaluation of pharyngeal airway space changes after bimaxillary orthognathic surgery with a 3-dimensional simulation and modeling program. Am J Orthod Dentofacial Orthop 2014; 146(4):477-92. https://doi.org/10.1016/j.ajodo.2014.06.017

[41] Kim MA, Kim BR, Youn JK, Kim YJ, Park YH. Head posture and pharyngeal airway volume changes after bimaxillary surgery for mandibular prognathism. J Oral Maxillofac Surg 2014; 42(5):531-5. https://doi.org/10.1016/j.jcms.2013.07.022

[42] Vancan RN, Zotarelli Filho IJ, Kassis EN. Major approaches of orthognathic surgery in obstructive sleep apnea syndrome: a systematic review. Health Sci J 2019; 13(4):1-4.

[43] Faria AC, Xavier SP, Silva Jr SN, Trawitzki LV, de Mello-Filho FV. Cephalometric analysis of modifications of the pharynx due to maxillo-mandibular advancement surgery in patients with obstructive sleep apnea Int $\mathrm{J}$ Oral Maxillofac Surg 2013; 42(5):579-84. https://doi.org/10.1016/j.ijom.2012.10.002 